\title{
Detection and tracking of moving object using modified background subtraction and Kalman filter
}

\author{
Jeevith S. H. ${ }^{1}$, Lakshmikanth S. $^{2}$ \\ ${ }^{1}$ Research Scholar, Visvesvaraya Technological University, India \\ ${ }^{2}$ Department of ECE, Acharya Institute of Technology, India
}

\begin{tabular}{l} 
Article Info \\
\hline Article history: \\
Received Jan 17, 2020 \\
Revised Jun 22, 2020 \\
Accepted Jul 12, 2020 \\
\hline Keywords: \\
Background subtraction (BG) \\
Computer vision (CV) \\
Frame differencing (FD) \\
Kalman filter (KF) \\
Moving object detection and \\
tracking
\end{tabular}

Article Info

Article history

Received Jan 17, 2020

Revised Jun 22, 2020

Accepted Jul 12, 2020

\section{Keywords:}

Computer vision $(\mathrm{CV})$

Frame differencing (FD)

Moving object detection and

\section{Corresponding Author:}

Jeevith S. H.,

Research Scholar,

Visvesvaraya Technological University

Belagavi, India.

Email: jeevithshbp@gmail.com

\begin{abstract}
Moving object detection and tracking (MODT) is the major challenging issue in Computer Vision, which plays a vital role in many applications like robotics, surveillance, navigation systems, militaries, environmental monitoring etc. There are several existing techniques, which has been used to detect and track the moving object in Surveillance system. Therefore it is necessary to develop new algorithm or modified algorithm which is robust to work in both day and night time. In this paper, modified BGS technique is proposed. The video is first converted to number of frames, then these frame are applied to modified background subtraction technique with adaptive threshold which gives detected object. Kalman filter technique is used for tracking the detected object. The experimental results shows this proposed method can efficiently and correctly detect and track the moving objects with less processing time which is compared with existing techniques.
\end{abstract}

This is an open access article under the CC BY-SA license.

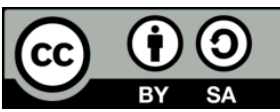

\section{INTRODUCTION}

Video surveillance is the most significant research area in CV which is used to identify and track moving objects in video. MODT has a large variety of application in computer vision such as compression of video, vision based control, visual surveillance, human computer interfaces, robotics and medical image processing [1-4]. MODT in video is an important challenging task within the area in CV. It is the process of analyzing video frames and estimation of position of the object, finally find the objects trajectory. There are 3 basic approaches in object detection, they are frame differencing (FD), Optical flow and background subtraction (BGS) [2-4]. FD is the simplest technique to calculate the difference between two consecutive frames. It can have strong flexibility for sudden environment change, but difficulty to recognize the object's shape and object in stationary. This method is not accurate [5]. Optical flow is the technique which is used to analyze the image vector field of moving object and possess clustering based on optical flow distribution characteristics of image. Using this technique, the complete information of an object movement and object detection from background can be obtained betterly. But it has more complex calculation, poor in anti-noise performance. As result, it is not suitable for real time applications [6-7]. BGS method is the simple technique to identify objects in motion. It is very sensitive to the illumination change and also has poor anti-interference ability [8-10].

Parameters affected on Existing detection techniques such as sudden change in object motion, scene illumination, objects shadow, camera clarity in motion [11-13]. Scene illumination change is a challenge for 
BGS, such as sudden change in climate, night, etc [14-18]. From number of years, various BGS techniques have been proposed by many researchers that main focus is to build more effective background model to handle it [20-25].

In order to overcome this problem, modified BGS is used in this paper to achieve higher level computer vision-based system using kalman filter (KF) [19]. First, it must be robust against scene illumination change. Second, it should avoid detecting moving background objects such as moving leaves, rain, snow, and shadows cast by moving objects [17-18]. The following sections are as follows: Section 2 describes prop, section 3 describes results and analysis and section 4 describes conclusion.

\section{PROPOSED METHODOLOGY}

The proposed block diagram of moving object detection and tracking is shown in Figure 1. The flowchart of proposed methodology is as shown in Figure 2. Initially the input video is taken from database. Frames can be extracted from input video, then modified BGS is applied to identify the object movement by using adaptive threshold. Detection of objects is realized by subtracting background image from every frame of video using modified BGS .

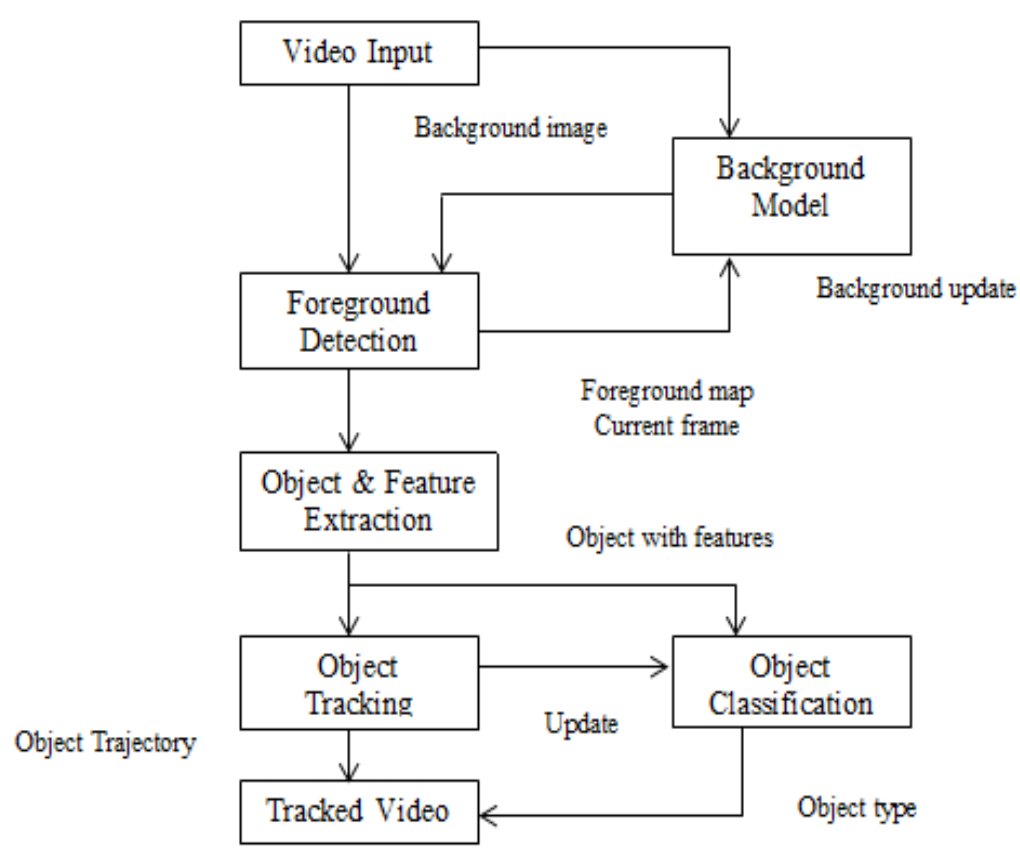

Figure 1. Proposed block diagram using modified background subtraction

Formula for Image subtraction: Subtracted Image $=I(x, y)-B(x, y)$.

Modified Background Subtraction $=\left\{\begin{array}{l}\text { Subtracted Image; if Subtracted Image } \geq \text { Adapt }_{\text {th }} \\ 0 ; \text { if Subtracted Image }<\text { Adapt }_{\text {th }}\end{array}\right.$

Where $\mathrm{I}(\mathrm{x}, \mathrm{y})$ is the foreground frame and $\mathrm{B}$ is the Background frame. Adpt $\mathrm{t}_{\mathrm{th}}$ is an adaptive threshold.

When $|\mathrm{I}(\mathrm{x}, \mathrm{y})-\mathrm{B}(\mathrm{x}, \mathrm{y})|>\mathrm{Adpt}_{\mathrm{th}}$, pixels are defined as foreground objects. Similarly, when $\mid \mathrm{I}(\mathrm{x}, \mathrm{y})-$ $\operatorname{Bt}(\mathrm{x}, \mathrm{y}) \mid<\mathrm{Adpt}_{\mathrm{th}}$, pixels are defined as background. Finally, the result is a detected object in foreground frame.

In this paper, the background image always changes due to the changes in object movement and other environment disturbance. So we need continually update the background image. Using an adaptive threshold, the movement of objects can be detected correctly under sudden change in illumination. Morphological operation is a technique of extracting object from frame that are useful in the object shape and representation and region shape description, such as boundaries, skeletons, and so on. It removes noise in detected object by dilation and erosion. 


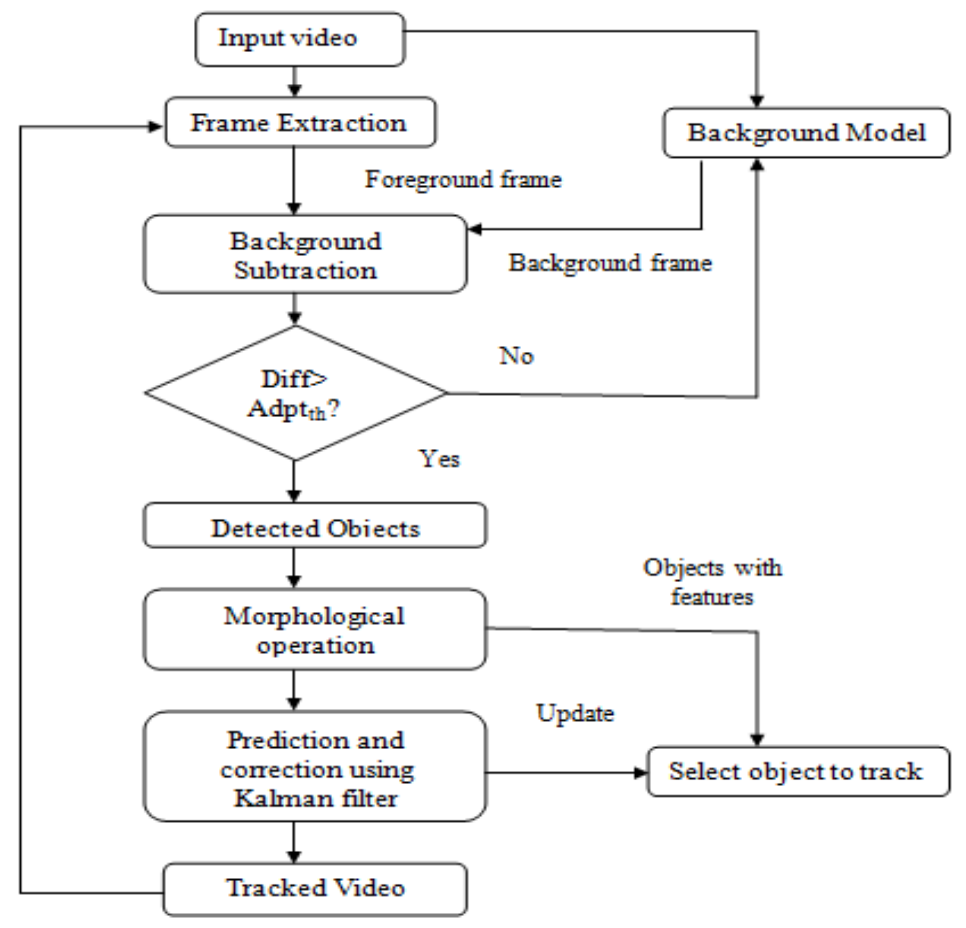

Figure 2. Flowchart of object detection and tracking

\subsection{Kalman filter}

After the morphological operation, target object can be tracked using Kalman filter in Figure 2. It can be a straight ideal standing estimation approach that is thought along about the preeminent realized hypothesis channel speculations [2][7]. Standing condition can be a straight outline of $w_{k}, u_{k-1}$ and $x_{k-1}$. Observation condition might be a direct delineation of $\mathrm{x}_{\mathrm{k}}$ and $\mathrm{v}_{\mathrm{k}}$. A powerful model is given standing condition and perception condition through the solid estimation redressed by estimations [2]. Kalman channel (methodical) standing condition is printed as pursue:

$$
\mathrm{x}_{k}=\mathrm{A}_{\mathrm{x}_{k-1}}+\mathrm{B}_{\mathrm{u}_{k-1}}+w_{k}
$$

Observation equation is defined as follow:

$$
z_{k}=H_{x_{k}}+v_{k}
$$

In the higher than recipes: $\mathrm{v}_{\mathrm{k}}, \mathrm{z}_{\mathrm{k}}, \mathrm{A}, \mathrm{H}, \mathrm{w}_{\mathrm{k}}, \mathrm{u}_{\mathrm{k}-1}, \mathrm{v}_{\mathrm{k}}$ is the standing vector, the perception vector, the standing change network, the perception framework, the framework commotion vector, the framework the board vector, the perception clamor vector, severally. $\mathrm{w}_{\mathrm{k}}$ and $\mathrm{v}_{\mathrm{k}}$ zone unit expected to fulfill positive unmistakable, parallel and random, zero mean researcher racket vector; $\mathrm{k}$ can be a subscript; wk and $\mathrm{z} \_\mathrm{k}$ territory unit happy:

$$
\begin{aligned}
& \mathrm{E}(\mathrm{w})=0, \operatorname{cov}(\mathrm{w})=\mathrm{E}\left(\mathrm{ww}^{\mathrm{T}}\right)=\mathrm{Q} \\
& \mathrm{E}(\mathrm{v})=0, \operatorname{cov}(\mathrm{v})=\mathrm{E}\left(\mathrm{vv}^{\mathrm{T}}\right)=\mathrm{R}, \mathrm{E}\left(\mathrm{wv}^{\mathrm{T}}\right)=0
\end{aligned}
$$

$-\mathrm{k} \in \mathrm{Rn}$ is sketched out because of the past standing estimation got from standing progress condition right now of $\mathrm{k}-1, \mathrm{x}_{\mathrm{k}}$ is printed because of the back standing estimation joins the estimations right now of $k$. The deviations unit of estimation appeared in condition (6) and condition (7):

$$
\mathrm{e}_{\mathrm{k}}^{-}=\mathrm{x}_{\mathrm{k}}-\mathrm{x}^{-\mathrm{k}}
$$




$$
\mathrm{e}_{\mathrm{k}}=\mathrm{x}_{\mathrm{k}}-\mathrm{x}^{\mathrm{k}}
$$

The priori and back estimation deviation co-variance conditions can be characterized as condition (8) and condition (9):

$$
\begin{aligned}
& p_{k}^{-}=E\left[e_{k}^{-} e_{k}^{-T}\right] \\
& p_{k}=E\left[e_{k} e_{k}^{T}\right]
\end{aligned}
$$

We should see standing $\mid \mathrm{a}$ standing \} estimation condition $\mathrm{x}_{\mathrm{k}}$ that ascertain the back standing estimation in this manner on prompt the Kalman channel conditions. It needs the computation equation of $\mathrm{x}_{\mathrm{k}}$ is that the straight mix of from the earlier estimation and weighted qualification between obvious estimations and estimated figure esteem. the following forecast and update conditions from the Kalman channel hypothesis unit of estimation got. Forecast conditions unit of estimation made open as pursues:

$$
\begin{aligned}
& \mathrm{x}_{\mathrm{k}}=\mathrm{Ax}_{(\mathrm{k}-1)}+\mathrm{Bu}_{(\mathrm{k}-1)} \\
& \mathrm{p}_{\mathrm{k}}=\mathrm{AP} \\
& (\mathrm{k}-1) \\
& \mathrm{A}^{\mathrm{T}}+\mathrm{Q}
\end{aligned}
$$

Equations defined here:

$$
\begin{aligned}
& \mathrm{K}_{\mathrm{k}}=\mathrm{p}_{\mathrm{k}}^{-} \mathrm{H}^{\mathrm{T}}\left(\mathrm{Hp}_{\mathrm{k}}^{-} \mathrm{H}^{\mathrm{T}}+\mathrm{R}\right)^{-1} \\
& \mathrm{X}_{\mathrm{k}-1}=\mathrm{x}_{\mathrm{k}}^{-}+\mathrm{K}_{\mathrm{k}}\left(\mathrm{z}_{\mathrm{k}}-\mathrm{H}_{\mathrm{k}}^{-}\right) \\
& \mathrm{p}_{\mathrm{k}}=\left(\mathrm{I}-\mathrm{K}_{\mathrm{k}} \mathrm{H}\right) \mathrm{p}_{\mathrm{k}}^{-}
\end{aligned}
$$

where $\mathrm{K}_{\mathrm{k}}, \mathrm{x}_{\mathrm{k}}, \mathrm{p}_{\mathrm{k}}$, I is that the Kalman gain network, ideal channel worth, channel deviation framework, corner to corner lattice.

\begin{tabular}{|c|c|c|c|c|}
\hline & $\begin{array}{c}\text { Frame } \\
\text { Difference }\end{array}$ & $\begin{array}{l}\text { Optical } \\
\text { Flow }\end{array}$ & $\begin{array}{l}\text { Background } \\
\text { Subtraction }\end{array}$ & $\begin{array}{l}\text { Modified Background } \\
\text { Subtraction }\end{array}$ \\
\hline Accuracy $(\%)$ & 15.13 & 16.77 & 92.70 & 99.27 \\
\hline IoU & 72 & 66 & 74 & 76 \\
\hline Frame per second & $4.38 \mathrm{e}-01$ & $4.74 \mathrm{e}-01$ & $3.79 \mathrm{e}-01$ & $3.88 \mathrm{e}-01$ \\
\hline Processing time (sec) & 180.36 & 195.5 & 156.32 & 151.3 \\
\hline Total number of Frames & 412 & 412 & 412 & 412 \\
\hline False frame rate & 164 & 20 & 65 & 57 \\
\hline
\end{tabular}

\section{RESULTS AND ANALYSIS}

The proposed work is implemented in Matlab. The two video datasets are used in the proposed work. It provides ground-truth markings and annotation with various attributes like occlusion, background clutter, rotation, Scene illumination change etc. on video sequences. In this paper, Analysis of different detection algorithm is done for different datasets using Kalman filter. From comparative result Table 1, accuracy of modified BGS method is more than other 2 methods.

Table1.Comparative result of all detection methods for walking dataset

We have quantitatively evaluated our detection algorithms using parameters: Accuracy, Intersection over Union (IoU), Frames per second (FPS), False frame Detection (FD) rate. Figure 3 show is the segmented image using Frame differencing technique, Figure 4 shown in the segmented image using optical flow technique and Figure 5 shown in the segmented image using modified BGS technique. For night dataset, this proposed work is implemented, which could extract moving objects from the low illumination video. From Table 2 result analysis of BGS is also done using Kalman filter in night time. 

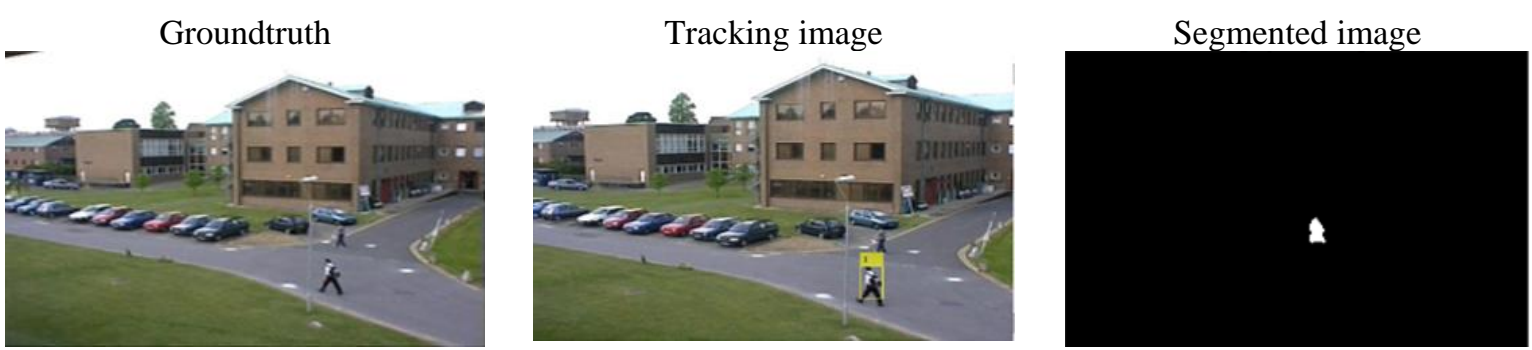

Figure 3. Segmented result of frame difference
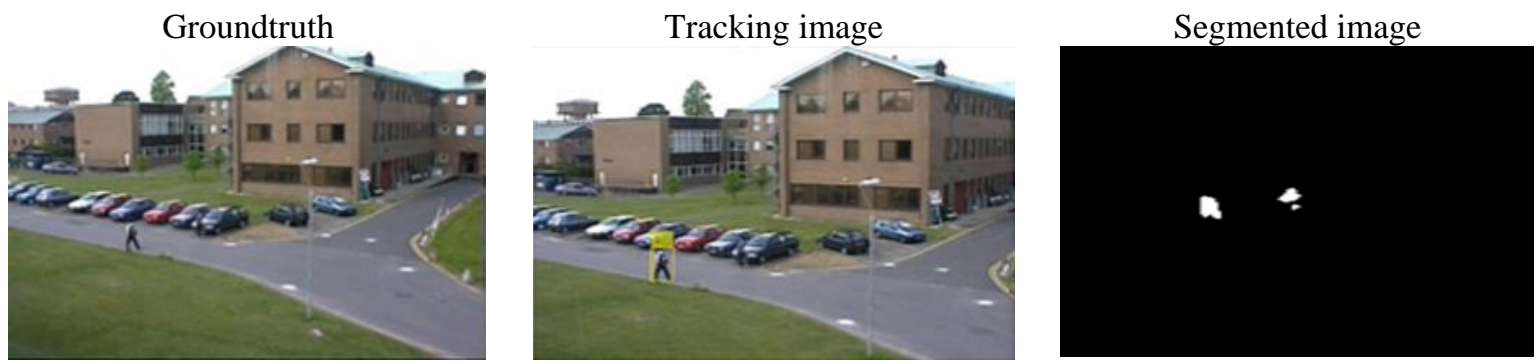

Figure 4. Segmented result of optical flow
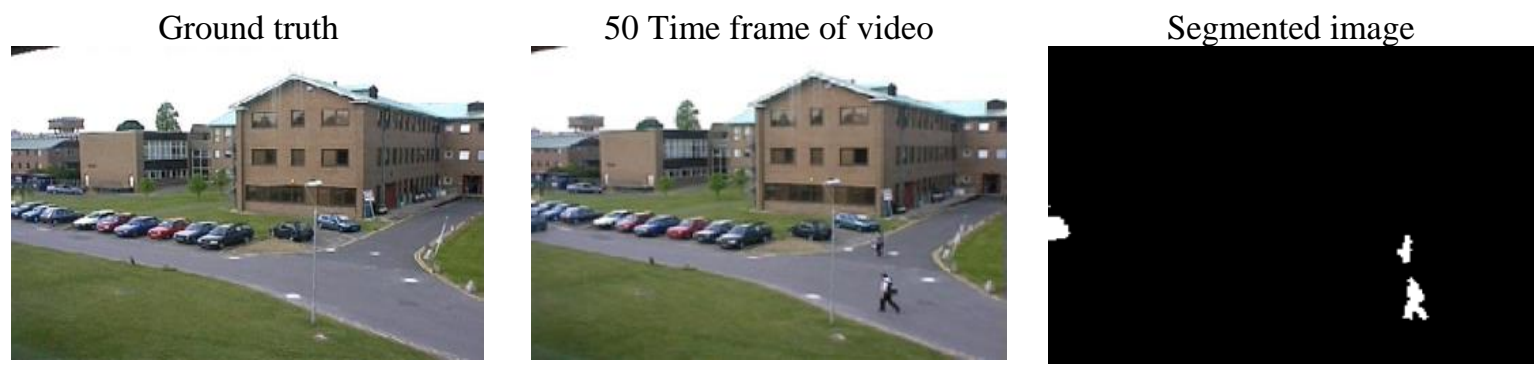

Figure 5. Segmented result of modified background subtraction

Table2. Comparative result of all detection methods for night dataset

\begin{tabular}{ccccc}
\hline Night Video dataset & $\begin{array}{c}\text { Frame } \\
\text { Difference }\end{array}$ & $\begin{array}{c}\text { Optical } \\
\text { Flow }\end{array}$ & $\begin{array}{c}\text { Background } \\
\text { Subtraction }\end{array}$ & $\begin{array}{c}\text { Modified Background } \\
\text { Subtraction }\end{array}$ \\
\hline Frame per second & $1.47 \mathrm{e}+00$ & $2.47 \mathrm{e}-01$ & $3.22 \mathrm{e}-01$ & $2.60 \mathrm{e}-01$ \\
Overall processing Time & $4.05 \mathrm{e}+02$ & $1.39 \mathrm{e}+02$ & $1.82 \mathrm{e}+.02$ & $1.47 \mathrm{e}+02$ \\
Number of Frame & 378 & 1281 & 565 & 565 \\
Number of Frame & $500 \times 500$ & $500 \times 500$ & $500 \times 500$ & $500 \times 500$ \\
False frame rate & 22 & 29 & 80 & 180 \\
\hline
\end{tabular}

\section{CONCLUSION}

Moving object detection \& tracking for the dynamic environments especially in designing of video surveillance system is a challenging task in CV. In this paper, modified BGS is proposed using adaptive threshold for detection which is efficiently identify the moving object in foreground using background. In this proposed work, Kalman filter is used for tracking of moving object.

From result evaluation, it is manifest that the accuracy of proposed method is $99.2 \%$, which is better than existing techniques and also processing time is $1.47 \mathrm{e}+02$ which is less than existing techniques. Therefore the proposed method is robust and adaptable to work in day and night time efficiently. In future proposed method has to meet the real-time requirements. 


\section{REFERENCE}

[1] S. R. Balaji, S. Kartheyan, "A survey on Moving Object Tracking Using Image Processing," 11th international conference on intelligent systems and control, pp. 469-474, 2017.

[2] Shridevi. S. Vasekar, Sanjivani K. Shah, "Background Subtraction and Kalman Filter Algorithm for Object Tracking," Int. conference on Recent Trends in Image Processing and Pattern Recognition, pp. 194-202, 2019.

[3] H.S.G.Supreeth · Chandrashekar M. Patil," Efficient multiple moving object detection and tracking using combined background subtraction and clustering", Signal, Image and Video Processing, vol.12,no.6, pp. 1097-1105,2018

[4] A. A. Malik, A. Khalil, and H. U. Khan, "Object Detection and Tracking using Background Subtraction and Connected Component Labeling," International Journal of Computer Applications, vol. 75, no. 13, 2013

[5] Wenchao Liu, He Chen, Long Ma, "Moving object detection and tracking based on ZYNQ FPGA and ARM SOC," pp.1- 4, 2015.

[6] Trupti A. Chopkar, Shashikant Lahade, "Real Time Detection of Moving Object Based On FPGA," IOSR J. Electron. Commun. Eng, vol. 11, no. 1, pp. 37-41, 2016.

[7] S. Shantaiya, et al, "Multiple object tracking using kalman filter and optical flow," European Journal of Advances in Engineering and Technology, vol. 2, no. 2, pp. 34-39, 2015.

[8] Zaki Y. Abid, Thamir R. Saeed, and Sameir A. Aziez," Selection, Detection, and Tracking of Video objects Based on FPGA," International journal of Computer,Communication, Control and system Engineering, vol. 15, no.1, 2015.

[9] G. Sindhura Bhargavi, B.Praveen Kumar, and T. Kalyan, "Fast Background Subtraction Algorithm for Moving Object Detection \& Tracking in FPGA," Int. J. Software Hardware Res. Eng, vol. 2, no. 6, pp. 65-70, 2014.

[10] Poonam Gujrathi R, Arokia Priya, P. Malathi, "Detecting Moving Object Using Background Subtraction Algorithm in FPGA," Fourth International Conference on Advances in Computing and Communications, pp. 117-120, 2014.

[11] Abutaleb M. M, Hamdy. A, Abuelwafa. M. E., Saad E. M, "FPGA-based object extraction based on multimodal sigma-delta background estimation," 2nd International Conference on Computer, Control and Communication, pp. 1-7, 2009.

[12] M. Saad, A. Hamdy and M. M. Abutaleb, "FPGA-Based implementation of a Low Cost and Area Real-Time Motion Detection," 15th International Conference of Mixed Design MIXDES, pp. 249-254, 2008.

[13] Butler. D, Sridharan. S, Bove V. M., "Real-time adaptive background segmentation," IEEE International Conference on Acoustics, Speech, and Signal Processing, vol. 3, pp. 349-352, 2003.

[14] Li Q-Z., He D-X., and Wang B," Effective moving objects detection based on clustering background model for video surveillance," Proceedings of the 2008 Congress on Image and Signal Processing, vol. 3, pp. 656-660, 2008.

[15] Appiah K., Hunter A, "A single-chip FPGA implementation of real-time adaptive background model," IEEE International Conference on Field-Programmable Technology, pp. 95-102, 2005.

[16] Piccardi, M."Background subtraction techniques: a review," IEEE International Conference on Systems, Man and Cybernetics, vol .4, pp. 3099-3104, 2004.

[17] Cucchiara, R., Grana, C., Piccardi, M., Prati, A., "Detecting moving objects, ghosts, and shadows in video streams," IEEE Transactions on Pattern Analysis. Machine Intelligence, vol. 25, no.10, pp. 1337-1442, October 2003.

[18] Vladimir Y. Mariano et. al. "Performance Evaluation of object Detection Algorithm," 16th international conference proceeding on pattern recognition, vol. 3, 2002.

[19] Oliver, N.M., Rosario, B., Pentland, A.P, "A Bayesian computer vision system for modeling human interactions," IEEE Trans. Pattern Analysis. Machine Intelligence, vol. 22, no. 8, pp. 831-843, August 2000.

[20] Ya Liu, Haizhou Ai, and Guang-you Xu, "Moving object detection and tracking based on Background subtraction," International Society for Optics and Photonics In Multispectral Image Processing and Pattern Recognition, pp. 62-66, 2001.

[21] Stauffer C, Grimson W. E. L, “Adaptive background mixture models for real-time tracking," IEEE Computer Society Conference on Computer Vision and Pattern Recognition, vol. 2, pp. 637-663, 1999.

[22] Collins, R., Lipton, A., Kanade,T., "A system for video surveillance and monitoring," International Proceedings of American Nuclear Society (ANS) Eighth International Topical Meeting on Robotic and Remote Systems, pp. 25-29, 1999.

[23] Alan J. Lipton, Hironobu Fujiyoshi, and Raju S. Patil., "Moving target classification and tracking from real-time video," Proceedings fourth IEEE workshop on applications of computer vision, pp. 8-14, 1998.

[24] Haritaoglu I, Harwood D, Davis L. S, "W4: Who? when? where? what? A real time system for detecting and tracking people," Proceedings Third IEEE International Conference on Automatic Face and Gesture Recognition, pp. 222-227, 1998.

[25] Wren C. R, Azarbayejani A, Darrell T, Pentland A.P,"Pfinder: real-time tracking of the human body," IEEE Transactions on Pattern Analysis and Machine Intelligence, vol. 19, no 7 , pp. 780-785, Jul. 1997. 


\section{BIOGRAPHIES OF AUTHORS}

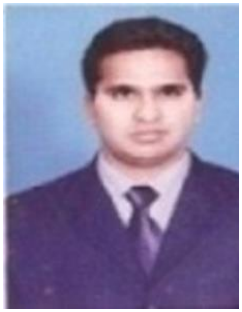

Mr. Jeevith S. H. is a Research Scholar at VTU, Belagavi, Karnataka, India. He has pursed B.E (Telecommunication Engineering) and M.Tech (VLSI and Embedded System) from VTU in the year 2009 and 2012 respectively. He is working as Assistant professor, Dept. of Electronics \& Telecommunication Engineering, SSIT, Tumakuru, Karnataka, India. He has working experience of more than 7 years. His area of research interest are Image processing and VLSI. $\mathrm{He}$ is the member of AMIE.

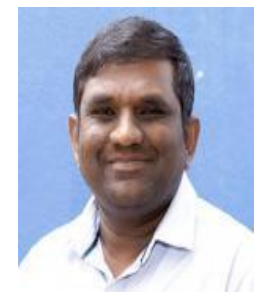

Dr. Lakshmikanth. S. has pursed his B.E (EEE) and M.Tech (CAID) from VTU, Belagavi, Karnataka, India, in the year 2002 and 2007 respectively. He has been awarded Ph.D in Jain university, Bengaluru, Karnataka in theb year 2015. He is currently working as Asociate professor, Dept. of ECE, Acharya Institute of Technology, Bengaluru, Karnataka. He has working experience of more than 18years. His area of research interest are Signal processing, Signal Denoising, Power Electronics and Control system.He is the member of MIE and MISTE. 